\title{
Revista
}

(RopP) Gestão \& Políticas Públicas

Artigo

\section{Políticas Públicas Sobre Drogas e População de Rua: humanização ou coisificação dos sujeitos?}

Policies on drugs and homeless population: humanization or reification of subjects?

Políticas Públicas Sobre Drogas y Población Callejera: ¿humanización o cosificación de los sujetos?

Bruna Suruagy Dantas ${ }^{1}$, Maria Teresa M. Turibio², Rafael Sorrentino Atanes ${ }^{3}$, Raphael Sapiensa de Almeida ${ }^{4}$

\footnotetext{
${ }^{1}$ Filiação institucional. Doutora em Psicologia Social pela Pontifícia Universidade Católica de São Paulo professora do curso de psicologia da Universidade Presbiteriana Mackenzie, São Paulo - SP, Brasil.

Correspondência: $\quad$ E-mail: brunasuruagy@gmail.com

Instituição de correspondência

Universidade Presbiteriana Makenzie - Faculdade de Psicologia - Rua da Consolação, 930 - CEP: 01302-907 - São Paulo - SP - Brasil
}

\footnotetext{
2 Filiação institucional. Graduanda do curso de psicologia da Universidade Presbiteriana Mackenzie, São Paulo - SP, Brasil. Correspondência: $\quad$ E-mail: mateturibio@yahoo.com.br.
}
${ }^{3}$ Filiação institucional. Graduando do curso de psicologia da Universidade Presbiteriana Mackenzie, São Paulo - SP, Brasil. Correspondência: E-mail: rafaelsorrentino@hotmail.com

\footnotetext{
${ }^{4}$ Filiação institucional. Graduanda do curso de psicologia da Universidade Presbiteriana Mackenzie, São Paulo - SP, Brasil. Correspondência: $\quad$ E-mail: raphaelsapiensa21@hotmail.com
} 
Resumo

\section{Abstract}

Nos últimos anos, o consumo de substâncias psicoativas e os casos de dependência química ganharam evidência nacional, repercutindo no campo político, social e sanitário. Em decorrência dessa realidade, políticas públicas e programas governamentais, baseados em diferentes correntes teóricas e metodológicas, foram desenvolvidos para atender a população devastada pelo uso abusivo de substâncias psicotrópicas. O presente trabalho analisa dois equipamentos de saúde implantados no Estado de São Paulo (Moradia Assistida e Consultório de Rua), que oferecem atendimento às pessoas em situação de rua com histórico de dependência química. Mediante a observação dos serviços e a realização de entrevistas com os coordenadores, procurou-se compreender as formas de funcionamento organizacional, as propostas de intervenção, o cotidiano dos equipamentos, o tratamento oferecido, os discursos institucionais e a visão da instituição acerca dos usuários e da funcionalidade social das drogas.

Palavras-chave: População de rua, Dependência química, Moradia Assistida, Consultório de Rua.

In recent years, psychoactive drug use and cases of chemical dependency have been in evidence across Brazil, reverberating in the political, social and sanitary fields. Due to this reality, public policies and governmental programs, based on different theoretical and methodological lines, have been developed to meet the needs of the population devastated by psychotropic substance abuse. The present study analyze two health services implemented in the State of São Paulo (Moradia Assistida - Assisted Housing - and Consultório de Rua - Street Medical Office), which offer assistance to homeless people with a history of chemical dependency. By observing the services and 
interviewing the coordinators, the aim was to understand the forms of organizational operation, the intervention proposals, the services' daily routine, the treatment that is offered, the institutional discourses, and the institution's view about users and drugs' social functionality.

Keywords: Homeless population, Chemical dependency, Moradia Assistida, Consultório de Rua.

Resumen En los últimos años, el consumo de sustancias psicoactivas y los casos de dependencia química ganaram evidencia nacional, repercutiendo en el campo político, social y sanitario. En decorrencia de esa realidad, políticas públicas y programas gubernamentales, basados en diferentes correntes teóricas y metodológicas, fueran desarrollados para atender aa población devastada por el uso abusivo de sustancias psicotrópicas. El presente trabajo analiza dos equipamentos de salud implantados en el Estado de São Paulo (Moradia Assistida y Consultório de Rua), que ofrecen atención a las personas en situación de calle con histórico de dependencia química. Mediante la observación de los servicios y la realización de entrevistas con los coordinadores, se buscó comprender las formas de funcionamiento organizacional, las propuestas de intervención, el cotidiano de los equipamentos, el tratamiento ofrecido, los discursos institucionales y la mirada de la institución acerca de los usuarios y de la funcionalidad social de las drogas.

Palabras-clave: Población de Calle, Dependencia química, Vivienda Asistida, Consulta de Calle. 


\section{Introdução}

A população em situação de rua cresce de forma assustadora nas cidades brasileiras, especialmente nas regiões centrais das metrópoles. É constituída por pessoas que, por motivos diversos, não possuem recursos para satisfazer necessidades básicas, como alimentação, saúde e moradia. De acordo com dados oficiais da Prefeitura de São Paulo ${ }^{1}$ (FESP, 2012), em 2011 a população de rua na cidade correspondia a 14.478 pessoas, sendo que 6.765 estavam nas ruas e 7.713 em centros de acolhimento. Apesar de se tratar de uma população heterogênea, é possível estabelecer um perfil dos sujeitos que vivem nas ruas: o número de homens (82\%) é significativamente superior à quantidade de mulheres (13\%). Os adultos (7.002) superam, em número, os idosos (1.455), os adolescentes (221) e as crianças (212). A quantidade de indivíduos de cor branca nas ruas (25\%) é maior que a quantidade de pessoas de cor negra (21\%) e de cor parda (17\%). A maioria $(52,6 \%)$ é proveniente do Estado de São Paulo e os demais $(47,4 \%)$ originam-se de diferentes Unidades da Federação, prevalecendo os Estados da Bahia, de Pernambuco e de Minas Gerais. Ainda segundo levantamento realizado pela Prefeitura de São Paulo, alega-se que o desentendimento com familiares é a motivação mais comum para abandonar a moradia de origem; porém, não devem ser ignorados outros motivos como a perda de emprego e o consumo de álcool e drogas. Esse levantamento oficial pode induzir a conclusões equivocadas: a vida nas ruas é determinada exclusivamente por fatores psicossociais, negando, assim, os determinantes econômicos, políticos e sociais. Os documentos governamentais costumam apresentar explicações que naturalizam e individualizam a segregação social, fenômeno típico das sociedades neoliberais, urbanas, globalizadas e tecnicistas. Conforme Costa (2005), o Estado promove a higienização das cidades e a criminalização da população de rua, favorecendo a exclusão social e atribuindo a responsabilidade aos próprios sujeitos.

As pessoas em situação de rua enfrentam diariamente violência gratuita, variações climáticas, falta de acesso à água potável, alimentação irregular, sono inadequado, relações sexuais, ausência de locais para higiene pessoal e necessidades fisiológicas, violação dos direitos humanos, solidão e estigmatização. Em virtude da condição de absoluta pauperização, encontram-se em estado de debilidade física e mental, adquirindo patologias respiratórias, dermatológicas, sexuais e, especialmente, psiquiátricas. A "cidade de muros" fratura a rede social, os laços afetivos, o sentimento de pertencimento e a autoimagem desse grupo, lançado à própria sorte e abandonado pelo sistema de proteção social (Caldeira, 2000).

\footnotetext{
${ }^{1}$ Informações extraídas do "Censo da população em situação de rua na municipalidade de São Paulo" (2012), produzido pela Fundação Escola de Sociologia e Política e consultado no site oficial da Prefeitura de São Paulo em 30 de dezembro de 2012:

http://www.prefeitura.sp.gov.br/cidade/secretarias/upload/chamadas/censoecaracteriz 1338734690.pdf.
} 
Além das rupturas e perdas intersubjetivas, o indivíduo que vive na rua ainda tem que suportar o peso dos estigmas sociais por meio dos quais deixa de ser considerado "criatura comum e total", tornando-se "uma pessoa estragada e diminuída", digna de descrédito por ser portadora de "um defeito, uma fraqueza ou uma desvantagem" (Goffman, 2008:12). De acordo com Mattos e Ferreira (2004), as representações e os estereótipos construídos para qualificar a população de rua, reduzida à condição de "vagabunda, preguiçosa, incapaz, inútil, perigosa e louca", funcionam como instrumentos ideológicos que propiciam a reificação das identidades e a legitimação das relações de exploração e dominação, culpabilizando os próprios sujeitos por sua miséria e sofrimento psicossocial (Di Flora, 1987).

$\mathrm{Na}$ rua, desempregado e sem pagar impostos, o indivíduo enfrenta cotidianamente a condição de invisibilidade social, o sileciamento da própria história e a negação da sua humanidade. Não é visto como cidadão nem mesmo como humano. Geralmente, só é percebido quando causa algum tipo de incômodo, constrangimento ou interrupção da estabilidade cotidiana das camadas socialmente favorecidas. A forte associação entre a vida na rua e a questão da dependência química torna ainda mais negativa a representação dessa população no imaginário social. Associação que se revela verdadeira, na maioria dos casos; porém, sua explicação é comumente inadequada. Socialmente, costuma-se argumentar que a dependência extrema leva o sujeito à situação de rua. Entretanto, a relação de causa e efeito pode se mostrar inversa: devido à extrema vulnerabilidade social, o indivíduo em situação de rua tem dificuldade para suportar o sofrimento físico e psicológico sem algo que amenize a vivência da dura realidade.

Em relação ao uso e abuso de drogas, o modelo de "guerra às drogas", importado dos Estados Unidos - implementado pelo então presidente Richard Nixon, em 1971 - ainda é a forma mais usual de lidar com a questão no Brasil. Trata-se de um modelo fortemente proibicionista, que se pauta em pesquisas científicas para desenvolver ações no âmbito político, policial e sanitário, com o objetivo de eliminar a droga, definindo como única alternativa de tratamento a abstinência (Miranda, 2013). No entanto, como salienta Sodelli (2010), os resultados das políticas repressivas não foram satisfatórios nas últimas décadas, abrindo espaço para o surgimento de propostas diferentes, como a política de redução de danos, que defende a construção de intervenções na área da saúde, com o intuito de minimizar os efeitos danosos - direta ou indiretamente - ligados à dependência química. $O$ fracasso das intervenções disciplinares deve-se ao imperativo da abstinência, à moralização das condutas, à correção dos valores e à aniquilação do sujeito. Segundo Sodelli (2010), o uso das drogas não deve ser compreendido como um comportamento desviante, mas como uma possibilidade dentre tantas de amenizar a angústia e o desamparo, decorrentes da vulnerabilidade ontológica que caracteriza a existência humana.

Tendo em vista a relevância e atualidade dessa temática, o presente trabalho se propõe a analisar as práticas psicossociais em dois equipamentos de saúde que atendem à população de rua em situação de dependência química - a moradia assistida e o consultório de rua - a fim de apreender os sistemas ideológicos que as justificam e legitimam. Para isso, foram realizadas entrevistas semi-estruturadas com os coordenadores dos dois serviços de saúde com vistas a descrever e comparar suas propostas terapêuticas e 
discursos institucionais. Segundo Demo (2001), tal instrumento metodológico nos possibilita captar a dimensão dinâmica, profunda, intersubjetiva e dialética das representações, símbolos e ações, preservando seu sentido hermenêutico. Poupart (2008) acrescenta que os métodos qualitativos de modo geral favorecem o acesso do pesquisador à profundidade das experiências sociais e às contradições das narrativas, garantindo seu desvelamento e compreensão.

Com base nessa perspectiva metodológica, foram visitadas duas instituições de saúde, baseadas em políticas públicas e diretrizes governamentais distintas. A Moradia Assistida, fruto do Programa Centro Legal, acolhe ex-moradores da "Cracolândia" previamente internados em Comunidades Terapêuticas e posteriormente encaminhados a uma das unidades espalhadas pela cidade, com o objetivo de favorecer a reintegração social.

A Operação Centro Legal ocorreu no dia 03 de janeiro de 2012, com a atuação da Polícia Militar do Estado de São Paulo em parceria com a Polícia Civil, a Guarda Civil Metropolitana, a Tropa de Choque e a Cavalaria, contando ainda com a presença de cães farejadores, o helicóptero Águia, dois carros-pipa e quatro caminhões cata-bagulho. De acordo com o site oficial da Prefeitura de São Paulo², "é público e notório que a região central da cidade de São Paulo, conhecida anteriormente como centro antigo e hoje como Cracolândia, é uma chaga na cidade e na vida das pessoas que ali vivem". O objetivo principal da Operação não era a saúde da população de rua e sim a valorização do centro: "Depois de inúmeras vistorias ao local e conversas com as pessoas que ali viviam, entendeu o prefeito que não haveria recuperação do centro da cidade sem a recuperação das vidas daquelas pessoas".

Com o propósito explícito de revitalização do antigo centro de São Paulo, a Operação Integrada Centro Legal, comandada pela Polícia Militar, teve um caráter repressor e policialesco, deixando de ser um caso de saúde e uma questão social. Segundo declaração de Luiz Alberto Chaves de Oliveira, coordenador de Políticas sobre Drogas da Secretaria da Justiça e da Defesa da Cidadania, do Estado de São Paulo: "A falta da droga e a dificuldade de fixação vão fazer com que as pessoas busquem o tratamento. Como é que você consegue levar o usuário a se tratar? Não é pela razão, é pelo sofrimento. Quem busca ajuda não suporta mais aquela situação. A dor e o sofrimento fazem a pessoa pedir ajuda". O tratamento, por conseguinte, não resulta da escolha do sujeito, mas da imposição do Estado via aparato policial, tortura, privação social e desamparo assistencial ${ }^{4}$.

\footnotetext{
2 Dados obtidos no site oficial da Prefeitura de São Paulo, consultado no dia 30 de dezembro de 2012 : http://www.prefeitura.sp.gov.br/cidade/secretarias/controle urbano/programa centro legal/index.php?p=14668.

${ }^{3}$ Entrevista concedida ao Jornal Estado de São Paulo, em 05 de janeiro de 2012.

${ }^{4}$ Em tom de comemoração, o site oficial da Secretaria da Justiça e da Defesa da Cidadania, do Estado de São Paulo (http://www.justica.sp.gov.br/Noticia.asp?Noticia=5188), acessado em 25 de junho de 2013 , apresenta as seguintes informações, de natureza quantitativa, atualizadas em 13/02/2013: 1) Prisões em flagrante - 803; 2) Condenados capturados 224; 3) Abordagens policiais - 84.531; 4) Drogas apreendidas - 156,156kg; 5) Abordagens sociais, de saúde e por guardas municipais - 158.150; 6) Internações para tratamento de dependentes químicos - 1.363; 7) Encaminhamentos para serviços de saúde-13.061.
} 
O segundo equipamento pesquisado foi o Consultório de Rua, em São Bernardo, com intervenções de campo baseadas na proposta de redução de danos, cujo objetivo consiste em "melhorar o bem-estar físico e social dos usuários, minimizando prejuízos causados pelo uso das substâncias" (Moreira, Silveira \& Andreoli, 2006:813), não se propondo a eliminar totalmente o consumo de drogas, uma vez que parte do pressuposto de que não é possível uma sociedade sem drogas.

Os dois equipamentos anteriormente descritos possuem perspectivas antagônicas em relação à questão da dependência química, do tipo de tratamento destinado à população de rua e das políticas públicas dirigidas ao consumo abusivo de substâncias psicoativas, o que torna o material coletado ainda mais rico e abre a possibilidade de discussões mais abrangentes. A expectativa é de que se produza conhecimento científico sobre um assunto ainda pouco estudado, colaborando para a desestigmatização do "morador de rua" e o esclarecimento da função social das drogas, o que pode contribuir com o desenvolvimento de intervenções mais humanizadas, que não firam a dignidade dessa população e não restrinjam o exercício de sua cidadania.

\section{Saúde Coletiva e População de Rua}

Conforme Paim e Filho (1998), a área da saúde tem passado por sucessivos movimentos de recomposição de suas práticas sanitárias, decorrentes das articulações entre o Estado e a sociedade, como resposta às necessidades sociais que têm surgido ao longo da história. Os discursos sociais sobre a saúde emergiram na segunda metade do século XVIII, na Europa Ocidental, e definiram um conjunto de normatizações a serem seguidas individualmente, cuja aplicação estava fortemente ligada à higiene e à moralidade. Estabeleceu-se como responsabilidade do Estado a definição de políticas, leis e regulamentos referentes à saúde, relacionando, assim, os discursos e práticas de saúde ao âmbito jurídico-político.

No século posterior, a Revolução Industrial surgiu como processo macrossocial que causou grande impacto nas condições de vida e saúde dos europeus. Como resultado da organização, mobilização e consequente aumento do poder político das classes trabalhadoras, reivindicações relacionadas à saúde entraram em pauta nos movimentos sociais do período, especialmente na Alemanha, França e Inglaterra. Conforme Rosen (1980), entre os anos de 1830 e 1880, nasceu um movimento denominado Medicina Social, que entendeu a crise sanitária como um processo sociopolítico, concebendo a medicina como atuação política no plano individual e a política como ação da medicina no contexto social. Desse modo, a participação política tornou-se o principal mecanismo para efetuar transformações nas condições de vida e de saúde da população. Como argumenta Nunes (1994), a nova proposta criticava o reducionismo biológico, o desenvolvimento de práticas individuais, a relevância exclusiva dos médicos e a concentração das ações nos hospitais. 
Paralelamente, na Inglaterra e nos Estados Unidos, estruturou-se uma reação às correntes médicas de caráter social, conhecida como sanitarismo, cujos fundamentos baseiam-se no emprego da tecnologia e na utilização da racionalidade organizacional no desenvolvimento de atividades profiláticas (identificação dos riscos, saneamento, imunização e controle de vetores). Com o advento dos paradigmas microbiano e bacteriológico, o movimento sanitarista ganhou ainda mais notoriedade e a medicina, em virtude do risco do contágio, assumiu a função normativa e higienista de controle das condutas (Matos, 2000). Conforme Coelho (2010), nesse cenário de micróbios e bactérias, os determinantes naturais e biológicos das doenças parecem incontestáveis e assumem a centralidade do discurso médico, sendo, agora, necessários para captá-los sofisticados equipamentos tecnológicos. O laboratório serve de suporte à prática clínica e à realização do diagnóstico, localizando-se nos hospitais. A medicina, pautada na assepsia, profilaxia e tratamento, adota o cientificismo como paradigma e segue o modelo hospitalocêntrico, cujos personagens centrais são as instituições hospitalares e os médicos.

No início do século XX, por intermédio do Relatório Flexner, desenvolveu-se nos Estados Unidos uma profunda reflexão sobre as bases científicas da medicina, o que proporcionou a redefinição da educação e das práticas médicas de acordo com rígidos princípios racionais e tecnológicos. Esse modelo conceitual, baseado no tecnicismo, na racionalidade e no cientificismo, aprofundou a separação entre indivíduo e sociedade, privado e público, biológico e social, curativo e preventivo. Acentuaram-se a ênfase no indivíduo e no corpo, assim como a centralidade do médico e do hospital. A inauguração das primeiras escolas de saúde pública contou com investimentos do capital privado e instituições de grande porte, como a Fundação Rockfeller. Gradativamente, vai se consolidando uma medicina científica, privatista, organicista e especializada (Pagliosa \& Da Ros, 2008).

Segundo Paim e Filho (1998), nas décadas de 1940 e 1950, teve início uma reforma curricular dos cursos de medicina nos Estados Unidos, com o intuito de apresentar aos futuros profissionais os dispositivos da prevenção, justificando conceitualmente intervenções prévias ao surgimento de sinais e sintomas, em uma fase denominada pré-clínica. Trata-se da Medicina Preventiva, sucesso absoluto em seu país de origem que, a despeito dos esforços empreendidos em sua internacionalização, obteve pouca repercussão em outros países.

Nos anos de 1960, também nos Estados Unidos, são criados centros comunitários de saúde, administrados por organizações não lucrativas e subsidiados pelo governo federal. $O$ objetivo da intitulada Medicina Comunitária era realizar ações preventivas e prestar cuidados básicos aos moradores próximos aos centros de saúde. Alguns dos princípios da Medicina Preventiva são colocados em prática, com foco em setores sociais desfavorecidos, mas, ainda assim, sem oferecer resistência ao modelo de saúde convencional. 
Como apontam Neto e cols. (2009), em 1974, no Canadá, o Relatório Lalonde ${ }^{5}$ introduziu a noção de promoção da saúde e definiu quatro determinantes do processo saúde/doença: biologia humana, ambiente natural e social, estilo de vida e sistema de organização dos serviços. Não obstante o reconhecimento das múltiplas determinações das patologias, o documento governamental prestigiou os estilos de vida dos indivíduos e desenvolveu ações prescritivas, disciplinares e normatizadoras com vistas a modificar hábitos e atitudes pessoais. Definem-se práticas de autovigilância e autocontrole, o que promove uma espécie de despolitização e individualização das ações bem como um processo de culpabilização dos sujeitos.

É nesse contexto histórico que, a partir da década de 1970, o movimento da saúde coletiva começa a ser delineado na América Latina, com o propósito de identificar contradições na saúde pública institucionalizada, em seus aspectos teóricos e práticos. Para Paim e Filho (1998), a saúde coletiva é um campo científico de produção de conhecimentos e saberes referentes ao âmbito da saúde, marcado pela interlocução entre diversos pontos de vista e pela utilização de disciplinas distintas. No aspecto prático, realizam-se ações em diferentes organizações, instituições e contextos socioculturais, dentro e fora do espaço delimitado como pertencente à saúde. Tais ações de saúde (promoção, proteção, recuperação e reabilitação) também constituem uma prática social, já que o objeto da saúde coletiva se situa no limite entre o biológico e o social e abrange a investigação dos determinantes da produção social das doenças e da organização dos serviços de saúde.

De acordo com os autores, a saúde coletiva tende a ser definida como ciência ou disciplina científica; entretanto, os trabalhos epistemológicos mais recentes consideram-na um campo interdisciplinar e não exatamente uma disciplina científica, muito menos uma ciência ou uma especialidade médica. O marco conceitual da saúde coletiva vem sendo construído desde a década de 1970, como resposta aos movimentos de reforma, visando a produção científica articulada às práticas sociais. A despeito de sua delimitação provisória, a saúde coletiva realiza com profunda eficácia:

(...) o estudo do fenômeno saúde/doença em populações como processo social; investiga a produção e distribuição das doenças na sociedade como processos de produção e reprodução social; analisa as práticas de saúde (processo de trabalho) na sua articulação com as demais práticas sociais; procura compreender, enfim, as formas com que a sociedade identifica suas necessidades e problemas de saúde, busca sua explicação e se organiza para enfrentá-los. (Paim \& Filho, 1998:309).

Segundo Campos (2000), uma teoria sobre a produção da saúde deveria se utilizar de todas as práticas sanitárias e mecanismos sociais referentes à saúde, à enfermidade e à intervenção. Para o autor, o paradigma médico vigente deve ser criticado por ser um modelo

\footnotetext{
${ }^{5}$ Considerado o primeiro relatório governamental do mundo ocidental, que pos em questão o modelo biomédico de assistência à saúde e propos o desenvolvimento de um sistema de saúde que ultrapasse a perspectiva do tratamento das patologias.
} 
incompleto e não por ser anacrônico. De igual modo, a saúde coletiva apresenta limitações, dado que não é capaz de apreender o fenômeno saúde/doença em sua totalidade. Por conseguinte, não há como pensar a saúde, ignorando as contribuições da biologia, psicologia, sociologia e clínica. Portanto, um saber relacionado à saúde deve abranger a clínica, a epidemiologia e as ciências sociais, ao proporcionar uma visão mais ampla sobre o processo saúde/doença e favorecer o atendimento das demandas de acordo com suas particularidades. A articulação dos saberes e recursos provenientes dos mais diversos campos possibilitaria a produção da saúde em diferentes níveis: 1) transformações econômicas, sociais e políticas resultando em padrões saudáveis de existência; 2) promoção de saúde e prevenção de enfermidades; 3) clínica e reabilitação; 4) atendimento a situações de urgência e emergência.

O trabalho de promoção da saúde, prevenção de doenças, tratamento de patologias e reabilitação deve pautar-se nos princípios da universalidade, integralidade e equidade. De acordo com Carneiro Júnior et al. (2010), a universalidade depende da democratização do acesso aos serviços, que não se dá pela mera oferta de unidades de saúde, mas pelo atendimento de demandas específicas. A cidade, muitas vezes, apresenta uma disponibilidade significativa de equipamentos de saúde, mas não oferece tecnologias apropriadas às necessidades de cada segmento social. Conforme Carneiro Júnior e Silveira (2003), a heterogeneidade e a particularidade dos grupos sociais requerem 0 desenvolvimento de um conjunto de ações especiais, que envolvam a mudança de mentalidade da equipe, a capacitação dos agentes de saúde, a organização do processo de trabalho e a adoção de novas estratégias e instrumentos de intervenção. A população de rua é um caso emblemático, cuja acessibilidade depende da reestruturação dos serviços, que apresentam um sistema de fluxos e rotinas que funciona como verdadeiro obstáculo ao acesso desse segmento social. Em muitas unidades de saúde, os profissionais, para efetuar o cadastramento do usuário, exigem documentação, só atendem à demanda espontânea, apresentam uma atuação intersetorial limitada e possuem preconceitos em relação à população marginalizada. São necessárias, portanto, novas abordagens e novos processos de trabalho na atenção à saúde da população de rua, que considerem suas especificidades, garantindo, assim, a equidade do acesso aos serviços.

Como ressalta Carneiro Junior et al. (1998), obstáculos organizacionais, estruturais e humanos se erguem e impedem que se ofereça às pessoas em situação de rua um atendimento adequado às suas necessidades sanitárias: dificuldade de aproximação da equipe técnica em função da sujeira e do mau cheiro dos sujeitos, rigidez da rotina dos serviços, burocracia para agendamento, exigência de documentos e fechamento dos profissionais no espaço intramuros. Souza et al. alegam que, a despeito da recente implementação de políticas públicas emancipatórias e participativas, as práticas no campo da saúde ainda são isoladas, assistencialistas, paternalistas e centralizadas, reforçando e cronificando o estado de dependência dos indivíduos. Todavia, desde a implantação do programa "A Gente na Rua" em 2003, cujos objetivos consistem na garantia de acesso aos equipamentos de saúde e na oferta de atenção integral à população de rua, desenvolveramse debates institucionais e diretrizes governamentais que preconizam a participação coletiva na gestão dos serviços, o controle social, o respeito à diversidade, a articulação não 
hierarquizada e cooperativa dos diferentes saberes, a realização de ações intersetoriais e o estímulo ao protagonismo (CANÔNICO et al., 2007).

De acordo com Souza et al. (2007), verificam-se, no cotidiano de funcionamento dos equipamentos de saúde, contradições entre as políticas públicas e as práticas instituídas. As instituições costumam perceber a população de rua como "desprovida de tudo, inclusive de história, vontades, valores e costumes" (p. 813). Nesse cenário de absoluta escassez objetiva e subjetiva, a equipe incumbe-se de lhe fornecer tudo e acaba por lhe impor sistemas simbólicos, códigos de referência e parâmetros de conduta, restringindo, dessa forma, seu direito de escolha e sua liberdade de decisão. Prevalece, por conseguinte, uma concepção caritativa e paternalista de ação social e sanitária. No entanto, nos discursos cotidianos são articulados termos como emancipação, cidadania, geração de renda, direitos e rede social, o que evidencia um movimento - ainda incipiente - de substituição do assistencialismo filantrópico pelo protagonismo social, a potencialização dos sujeitos e o exercício da cidadania. Discursos que reforçam a participação social e o fortalecimento da cultura popular convivem com práticas higienistas e sanitaristas, que se pautam na remoção de grupos que ocupam as ruas das grandes cidades. Políticas paliativas, que cronificam a desigualdade e infantilizam os indivíduos, coexistem com programas humanizantes, que promovem autonomia (SOUZA et al., 2007).

\section{Moradia Assistida: tecnologia de repressão e disciplina}

O Programa Centro Legal tem como objetivo oferecer tratamento de saúde, prestar atendimento psicológico, restaurar relações familiares e promover a reinserção social das

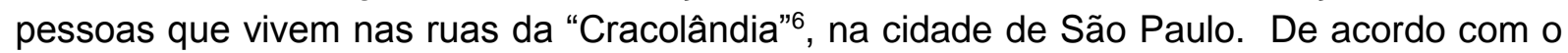
site da Prefeitura de São $\mathrm{Paulo}^{7}$, a região central, anteriormente conhecida como centro econômico, encontra-se em estado de degradação em virtude das "pessoas que ali vivem". Em função da deterioração moral, social e econômica da região, em 2006, no governo de José Serra, iniciou-se a primeira fase do programa - chamada Nova Luz - que consistiu na desapropriação de imóveis e locais, que "incentivavam a prostituição, abrigavam traficantes e dependentes químicos".

No ano de 2009, o então prefeito Gilberto Kassab ampliou o alcance do projeto, ao perceber que "não haveria recuperação do centro da cidade sem a recuperação das vidas daquelas pessoas, que não bastaria apenas reformular fisicamente o centro da cidade.

\footnotetext{
${ }^{6}$ A área central de São Paulo era o epicentro econômico da cidade; porém, com a diminuição considerável dos investimentos e o aumento da população de rua no local, foi batizada informalmente de Cracolândia, devido ao alto consumo de crack na região.

${ }^{7}$ Informações extraídas do site oficial da Prefeitura de São Paulo, acessado em 20 de dezembro de 2012: www.prefeitura.sp.gov.br/cidade/secretarias/controle urbano/programa centro legal/index.php?p=14668
} 
Tinha que se acolher e atender as pessoas que ali viviam, dando-lhes uma nova oportunidade de vida". Com base nessas assertivas, constata-se que o objetivo do programa é a revitalização física e econômica do centro, o que denota a política de higienização adotada pela gestão pública municipal. Logo, o tratamento oferecido às pessoas que ali se encontram é apenas um meio de alcançar esse fim.

Ainda segundo o texto de apresentação do programa, a desagregação familiar é um aspecto sempre presente no perfil do sujeito que vive na rua e é dependente químico. Por isso, o projeto prevê também o tratamento dos familiares de cada paciente, quebrando, assim, o círculo vicioso de "viver nas ruas - tornar-se dependente de álcool e drogas envolver-se com a criminalidade - perder a dignidade - ser excluído socialmente - ter uma desagregação familiar completa".

O projeto se inicia com abordagens nas ruas, realizadas por agentes comunitários e agentes de proteção urbana, cuja ação consiste em oferecer tratamento ao dependente químico e convencê-lo a aceitar. O CRATOD ${ }^{8}$, a $\mathrm{AMA}^{9}$ Sé e a AMA Boraceia são as portas de entrada do sujeito na rede de assistência, onde são feitos atendimento clínico e avaliação do estado de saúde do paciente, para posterior encaminhamento a uma clínica ou comunidade terapêutica. Desintoxicados e abstinentes, os usuários então podem ser selecionados para residir em uma das cinco unidades de Moradia Assistida (Capela do Socorro, Jabaquara, Ipiranga, Penha e Santana), o último equipamento previsto pelo Programa, que visa à reintegração social do indivíduo.

A idealização da Moradia Assistida já fazia parte do Programa Centro Legal, mas sua concretização foi acelerada pela Operação Integrada Centro Legal, iniciada no dia 3 de janeiro de 2012, tendo como consequência o aumento da demanda por atendimento aos usuários de crack, na região central da cidade. Segundo Martins e Vieira (2012), a ação teve um caráter repressor, com comando da Polícia Militar e utilização de cavalaria, balas de borracha e bombas de gás lacrimogêneo. Para os autores, houve excesso de violência na abordagem aos dependentes e, como consequência, dezenas de denúncias de abuso policial foram coletadas pela Defensoria Pública de São Paulo, nos primeiros dias da operação. Os agentes de saúde e assistência social também participaram da ação, oferecendo tratamento à população de rua somente após a intervenção inicial da Polícia, o que reforça a ideia de que as demandas terapêuticas e sociais tiveram importância secundária na operação.

A inauguração oficial da Moradia Assistida ocorreu no dia 16 de maio de $2012^{10}$, embora a coordenadora entrevistada tenha afirmado que sua unidade funciona desde abril, mesmo "faltando algumas coisas" [sic]. O objetivo principal do projeto, conforme

\footnotetext{
${ }^{8}$ Centro de Referência de Álcool, Tabaco e Outras Drogas.

${ }^{9}$ Assistência Médica Ambulatorial.

10 Dados obtidos no site: http://participacaoeparceria.blogspot.com.br/2012/05/smpp-promove-lancamento-do-projeto.html, acessado em 9 de dezembro de 2012.
} 
apresentado pela Prefeitura em seu site oficial ${ }^{11}$, é "garantir o acolhimento institucional de pessoas em situação de rua abordadas pelo projeto Centro Legal, servindo de referência como moradia para os usuários em tratamento de saúde e de assistência para a reinserção social dos mesmos". O indivíduo é auxiliado na aquisição de documentos e em outros procedimentos necessários à conquista de emprego e desenvolvimento da autonomia. Busca-se ainda o resgate do vínculo familiar do sujeito como parte de sua reintegração social. A expectativa é de que esse processo se realize no prazo máximo de seis meses.

Cabe à equipe técnica tomar medidas para que as regras de convivência, estabelecidas contratualmente, sejam respeitadas pelos moradores. Além disso, há a organização de uma agenda semanal de atividades, em que constam: programas de educação supletiva, oficinas de terapia ocupacional, cursos de informática e do SENAI ${ }^{12}$, regulamentação de documentos, entre outras atividades definidas de acordo com a demanda do usuário.

A avaliação e o monitoramento do serviço são realizados através de relatórios, contendo as seguintes informações: níveis de autonomia e autocuidado de cada indivíduo adquiridos no mês referido; número e tipo de encaminhamentos efetuados; eventuais dificuldades de relacionamento com outros moradores ou fora da casa; grau de participação nas atividades desenvolvidas e envolvimento na manutenção do espaço individual e coletivo.

Ainda de acordo com o projeto, as moradias devem se encaixar em uma das seis modalidades descritas: 1) Mulheres adultas com grau suficiente de autonomia e discernimento (15 vagas); 2) Mulheres adultas com médio e baixo grau de autonomia e discernimento (10 vagas); 3) Homens adultos com grau suficiente de autonomia e discernimento (15 vagas); 4) Homens adultos com médio e baixo grau de autonomia e discernimento (15 vagas); 5) Famílias com grau suficiente de autonomia e discernimento (3 vagas); 6) Famílias com médio e baixo grau de autonomia e discernimento (3 vagas).

Os dados fornecidos na entrevista acerca da estruturação do serviço divergem das orientações e diretrizes estabelecidas pelo projeto. Primeiramente, o critério relacionado ao grau de autonomia não parece utilizado na definição dos encaminhamentos. Indagada sobre a determinação desse critério, a coordenadora demonstrou utilizar parâmetros específicos, baseados em sua experiência e na especificação dos estágios motivacionais do dependente químico: pré-contemplação, contemplação, ação e manutenção, sendo o último estágio característico da situação em que se encontram os moradores da casa. Além disso, a unidade visitada funciona com no máximo 12 pessoas, número que não consta em nenhuma das seis modalidades apresentadas.

\footnotetext{
11 Informações extraídas do site oficial da Prefeitura de São Paulo, consultado em 9 de dezembro de 2012: http://www.prefeitura.sp.gov.br/cidade/secretarias/upload/chamadas/moradia assistida link para o site 1265141605.pdf.

${ }^{12}$ Serviço Nacional de Aprendizagem Industrial.
} 
De acordo com o relato da gerente, a abstinência é o pré-requisito fundamental para o indivíduo ser aceito e permanecer em uma das unidades. O rigor e a disciplina caracterizam o funcionamento do serviço: "aqui dentro não aceitamos de modo algum o consumo de drogas. É tolerância zero". Por isso, a fiscalização quanto ao uso de drogas é constante, com o estabelecimento de horários, a utilização de planilhas e a aplicação de testagens, determinadas pelo coordenador. A Moradia Assistida, como o próprio nome indica, funciona como um panóptico na acepção que Ihe conferiu Foucault (2006), realizando em tempo integral uma espécie de vigilância institucional, automatizada e desindividualizada, que controla e disciplina condutas.

Além da vigilância como estratégia de tratamento, a coordenadora referiu-se à importância da internação compulsória. Em sua concepção, quem não entende a necessidade da internação compulsória "obviamente não tem uma filha lá dentro". Caso tivesse uma filha nessas condições, a internaria mesmo contra sua vontade, pois os dependentes químicos não possuem capacidade de julgamento e avaliação de sua situação nem poder de decisão. Loureiro (2011) refuta esse argumento, constantemente utilizado para justificar a internação compulsória:

[...] por meu filho faria qualquer coisa porque não tem como eu não estar reativo, irracional a ponto de querer fazer qualquer coisa para salvá-lo. Como profissional, definitivamente, não faria o que poderia fazer para o meu filho, porque se espera que eu tenha um nível de envolvimento confortável o suficiente para não perder a noção de perspectiva e reflexão. Essa temperatura de consciência é o caminho que pode me oferecer a possibilidade de proporcionar um cuidado que seja diferenciado e não pautado no sensacionalismo, heroísmo e que, por outro lado, também não corra o risco de tomar o rumo de uma relação perversa, pautada silenciosamente num narcisismo que empurra muitas ações de ajuda ao outro, enquanto esta alimenta o reflexo do meu espelho (p. 123);

Segundo o autor, a patologização do consumo de crack contribui para o entendimento de que o usuário é um doente, alienado de si mesmo e, por isso, deve ser tratado a qualquer custo. Nos depoimentos da coordenadora e no modo como trata os usuários do serviço, verifica-se nitidamente a concepção patológica dos sujeitos, que gera um processo de infantilização, legitimando a necessidade de cuidado e a responsabilização pela vida do outro.

Além de infantilizado, o usuário é visto na Moradia Assistida como alguém que manipula e engana as pessoas próximas, com o objetivo de alimentar seu "vício". Por isso, o profissional deve estar sempre atento para não ser influenciado pelas "iscas emocionais" utilizadas pelos dependentes. Este discurso ideológico considera que, ao fazer uso de drogas, o sujeito perde sua consciência moral, não possuindo princípios éticos preservados.

Ao descrever o equipamento, a entrevistada salienta: "É tudo muito organizado", com planilhas de escala de serviços, "até pra tomar banho". Esta organização se caracteriza, principalmente, pela limpeza e controle, em oposição ao "submundo das drogas", com sua sujeira e imprevisibilidade. A psicóloga também relatou que tira fotos quando a casa está 
arrumada e desarrumada, perguntando em seguida aos moradores qual das duas casas preferem - prática que denota a utilização de uma política higienista.

Para Foucault (2006), a disciplina é uma técnica específica que toma os indivíduos como objetos, com o propósito de "fabricá-los" e moldá-los. Esta visão objetificada dos sujeitos ignora a complexa diversidade de fatores psíquicos e sociais responsáveis pela dependência, se limitando a culpabilizar o indivíduo, com seus comportamentos desviantes e socialmente indesejáveis. A objetificação dos sujeitos é demonstrada no seguinte relato da coordenadora: "Quem que muda comportamento? Nós, os psicólogos". Nega-se, pois, a participação do próprio sujeito nesse processo, cabendo-lhe apenas obedecer às injunções do psicólogo, cuja função consiste em transformar o comportamento mediante a utilização de técnicas específicas, que produzem alienação e desumanização. Além disso, a gerente declara que o papel do psicólogo se restringe a modificar comportamentos, fabricando indivíduos adaptados, o que contraria os princípios éticos da profissão, que prescrevem ao profissional não julgar o comportamento dos sujeitos nem tratá-los como coisa.

Conforme Foucault (2006), "o sucesso do poder disciplinar se deve sem dúvida ao uso de instrumentos simples: o olhar hierárquico, a sanção normalizadora e sua combinação num procedimento que lhe é específico, o exame" (p.143). Este poder disciplinar é encontrado nas formas de tratamento da Moradia Assistida. Ao culpar os usuários por sua condição, o equipamento se utiliza de diversos recursos punitivos e sistemas de vigilância, aplicados diante de qualquer deslize dos sujeitos. Segundo relato da entrevistada, as saídas não previstas na programação usual devem ser autorizadas por ela, com lugar e horário previamente determinados, e nessas ocasiões o morador deve assinar um documento se comprometendo a retornar à instituição. Se ele chegar depois do horário estipulado, a gerente o repreende; no entanto, "se chegar 21 horas e 1 minuto ${ }^{13}$, a gente já nem abre a porta". Nos casos de desobediência e má conduta, costuma-se fazer a testagem de drogas, mediante a utilização do bafômetro e a realização do exame de sangue, que pode ser determinada pela gerente a qualquer momento, com limite de duas testagens por mês para cada morador.

De acordo com a gerente, os moradores da casa participam de assembleias diariamente, com o intuito de discutir assuntos referentes à convivência e solucionar eventuais conflitos. As reuniões são dirigidas por ela e costumam ter duração de meia hora, ocorrendo mesmo quando não existem temáticas importantes, o que denota uma obrigatoriedade quanto à sua realização.

No que diz respeito à recaída dos dependentes, a psicóloga se mostrou inflexível. Em sua concepção, a recaída ocorre quando a pessoa some durante dias, sem nenhum tipo de aviso. Nessas ocasiões, normalmente, "a criatura toma todas" [sic]. Segundo Foucault (2006), instituições como a escola e o exército aplicam micropenalidades relacionadas ao tempo (atrasos, ausências, interrupções das tarefas), à maneira de ser (grosseria, 
desobediência) e ao corpo (atitudes tidas como incorretas, sujeira), as quais envolvem castigos físicos, privações e até mesmo humilhações. Ora, de acordo com a psicóloga do serviço, caso os moradores se atrasem ou desobedeçam suas ordens, ela lhes dá "uma bronca" e não os deixa entrar na moradia, sendo passível até de ser privado do tratamento.

Por fim, uma frase emblemática da coordenadora, que sintetiza o serviço oferecido na Moradia Assistida: "é um resgate da autonomia da pessoa". Etimologicamente, autonomia significa o poder de estabelecer a própria lei; autós (a si mesmo) e nomos (lei). Como já visto, o serviço prestado possui grande enfoque normativo; no entanto, essas normas sempre vêm de fora, da forte estrutura repressora e nunca é atribuição do próprio sujeito. Provavelmente, a autonomia a que a psicóloga se refere abrange apenas aspectos adaptativos ou, mais especificamente, financeiros, e não a capacidade das pessoas de guiar sua vida segundo as próprias leis.

\section{Consultório de Rua: a emergência do sujeito}

Segundo Plena et al. (2010), o consultório de rua surgiu em 1999 na cidade de Salvador, sendo desenvolvido pelo Centro de Estudos e Terapia do Abuso de Drogas (CETAD), como resposta às necessidades de crianças em situação de vulnerabilidade social e consumo de drogas. Inicialmente, propunha-se atender apenas crianças e adolescentes; porém, em virtude da percepção das demandas reais da população, a proposta foi ampliada para todas as faixas etárias.

O Consultório de Rua se constituiu como um equipamento que atende aos usuários de drogas em situação de rua, podendo garantir acessibilidade a esta população que, por consequência de sua condição social, dificilmente tem acesso ao sistema público de saúde. O depoimento do entrevistado salienta a importância desse serviço: "O nosso foco está nos sujeitos em situação de rua que são dependentes químicos, porque o problema é o cara que tá na rua pô, não o cara que tá em casa" [sic]. O estabelecimento de vínculo com os usuários é indispensável, porque possibilita a adesão ao tratamento e favorece a realização de encaminhamentos às unidades de saúde de modo que o sujeito tenha acesso à rede intersetorial. Logo, deve-se investir sobremaneira nos laços afetivos entre a equipe de saúde e a população de rua. Sodelli (2010) indica, como diretriz norteadora da relação dos agentes de saúde com o outro, a não utilização de estratégias de terror, amedrontamento e intimidação, pautadas na ideologia da mídia, cuja ênfase está no combate ao consumo de drogas. O entrevistado relata como se estabelecem os vínculos com os usuários: "Quando vamos fazer o acolhimento e tentar estabelecer o vínculo, nós nunca chegamos colocando medo. Tentamos sempre deixar o cara à vontade para ele ver que nossa proposta é diferente. Geralmente, chegamos em três agentes porque caso um não consiga estabelecer o vínculo, os outros que estão atrás ainda podem tentar" [sic]. Outra diretriz apontada pelo autor corresponde à prática de uma relação de dialogicidade, que contribui com a formação de uma consciência crítica, capaz de identificar possíveis riscos. 
O equipamento oferece cuidados em saúde aos usuários em seu próprio contexto de vida, assistência integral e promoção de laços sociais, possibilitando maior garantia de direitos e cidadania. Para desempenhar sua função comunitária, por se tratar de uma equipe itinerante, os agentes utilizam uma van própria do Consultório que, conforme o entrevistado, é seu grande diferencial. Esta van possui um logotipo em sua lateral, com o nome do equipamento, visando facilitar o reconhecimento por parte dos usuários e a identificação com o serviço e os agentes de saúde. São distribuídos aos sujeitos kits com produtos diversos para a promoção da saúde e prevenção de doenças, incluindo água, água de coco, chocolate, preservativo e protetor labial, evitando, dessa maneira, diversas patologias e até mesmo a desidratação.

Seu propósito é oferecer ao segmento de usuários de substâncias psicoativas em situação de maior vulnerabilidade a disponibilização de recursos para os cuidados básicos de saúde, atendendo-os em seus locais de permanência e encaminhando as demandas mais complexas para a rede de saúde. Nesse sentido, uma das suas funções é atuar como uma ponte para a população que está à margem do sistema de saúde e possibilitar sua inserção na rede. (Plena e cols., 2010:13).

Um dos princípios fundamentais que norteiam esta prática é a universalidade de acesso à saúde, pois os agentes vão ao encontro dos usuários para garantir-lhes o direito à assistência pública, inserindo-os na rede SUS. O serviço oferece atenção integral ao sujeito e pode acolher demandas de ordem física, psíquica e social. A equidade, outro princípio do SUS que sustenta a tese de que é necessário conceder mais possibilidades aos que menos têm, constitui um dos eixos éticos do Consultório de Rua, assegurando maior atenção aos sujeitos em situação de risco e vulnerabilidade social, que possuem as piores condições de saúde em geral.

Outro eixo ético se refere ao respeito ao modus vivendi da população atendida. Não cabe à equipe nenhuma forma de julgamento ou censura moral aos comportamentos dos indivíduos, seja com relação ao uso de substâncias psicoativas ilícitas, ou a condutas delinquentes ou antagônicas à moral e costumes tidos como aceitáveis. O papel dos profissionais é exatamente o de acessar um segmento que muitas vezes está à margem da rede de saúde e social por temer o estigma e a rejeição. A aceitação de cada um destes usuários enquanto sujeitos e o respeito ao lugar que ocupam na escala social confere ao Consultório de Rua a possibilidade de construção de um vínculo de confiança, base sobre a qual se desenvolverá o trabalho (Plena e cols., 2010:12).

Em paralelo à consolidação dos laços de confiança, utiliza-se como estratégia de intervenção a redução de danos, respeitando o tempo de cada um, valorizando a livre escolha e minimizando os danos, sem impor leis ou regras para o tratamento. $O$ entrevistado destacou as seguintes diferenças entre o Consultório de Rua e os demais equipamentos de saúde: a proposta de redução de danos, a negação do julgamento moral e a não utilização da punição nos casos de recaída. Em sua concepção, "até mesmo as 
recaídas são traços de liberdade dos usuários e o equipamento precisa manter essa liberdade".

Segundo Petuco (2010), a redução de danos é um conjunto de estratégias, criado para e por pessoas que consomem drogas, cujo objetivo consiste em minimizar possíveis consequências negativas do uso abusivo de substâncias lícitas ou ilícitas, sem se utilizar do recurso repressivo da abstinência.

Desse modo, o Consultório de Rua não impõe a abstinência ao usuário, respeitando os limites éticos mencionados acima, como se verifica na declaração do coordenador do serviço: "Tolerância zero aqui é crime. Nosso trabalho não é abstinência e nós não acreditamos nisso. Todos os casos de abstinência não dão certo e cristalizam, a verdade é que não existe. Nosso compromisso é com a saúde. Tem gente que pede para ser internado, mas nós entendemos como desintoxicação. Muitas vezes é um pedido da família, que assiste muita rede Globo e acha que só internando funciona”. Conforme seu depoimento, o Consultório de Rua tem por função auxiliar na reconstrução do sentido da existência. De acordo com Sodelli (2010), ao dialogar com outros interesses, distintos da proibição e do controle, modifica-se o tipo de prevenção e atendimento, pois na perspectiva da redução de danos não é o médico ou o psicólogo que determinam como o sujeito deve se prevenir, mas sim o próprio sujeito que, após uma intensa reflexão, busca encontrar suas melhores possibilidades e maneiras para mudar sua vulnerabilidade.

Segundo Sodelli (2010), ao tentar explicar o fenômeno das drogas, a sociedade adota uma perspectiva reducionista e simplificada que, na área da prevenção, utiliza recursos proibicionistas e pauta-se no princípio da abstinência como ferramenta principal. $O$ reducionismo caracteriza o projeto da Moradia Assistida que visa a abstinência a qualquer custo, diferenciando-se significativamente do Consultório de Rua que, por se basear na política de redução de danos, procura compreender o fenômeno humano em sua complexidade, sem restringi-lo ao princípio da abstinência, oferecendo uma assistência integral ao sujeito dependente químico. A perspectiva da redução de danos não propõe que o indivíduo interrompa o uso das substâncias psicoativas, mas almeja compreender a maneira como o consumo se realiza a fim de encontrar formas específicas de assistência, priorizando diminuir os possíveis danos à saúde e possibilitando ao sujeito escolhas mais autênticas e livres, que possam de alguma maneira reduzir suas condições de vulnerabilidade.

\section{Considerações Finais}

Com base nas entrevistas, na observação institucional e no levantamento previamente realizado dos dois equipamentos de saúde, constatam-se discrepâncias fundamentais no que diz respeito ao tratamento dos sujeitos em situação de rua com histórico de dependência química. A Moradia Assistida considera necessária a abstinência para a 
recuperação do usuário, enquanto o Consultório de Rua - com sua política de redução de danos - compreende o sujeito de forma integral, não exigindo a abstinência, com foco maior na promoção da saúde e diminuição dos prejuízos causados pelo uso abusivo de drogas.

Outra diferença essencial refere-se à questão do controle imposto pela Moradia Assistida, "produzindo" sujeitos domesticados, com comportamentos meramente adaptativos, sendo o confinamento, a vigilância e a punição as principais técnicas utilizadas pelo equipamento. Em contrapartida, o Consultório de Rua tem como princípio norteador do cuidado com o outro, a criação do vínculo, considerado imprescindível para a aderência ao tratamento, respeitando, assim, as vontades pessoais e a responsabilidade do usuário em conduzir sua própria vida. O vínculo é criado no próprio ambiente do indivíduo, que não possui acesso aos tradicionais serviços de saúde, garantindo, desse modo, atenção integral ao sujeito, de acordo com suas demandas específicas.

Em ambos os equipamentos, faz-se referência à reintegração social do usuário, concebendo-a como o principal objetivo do tratamento. Contudo, na Moradia Assistida, a reintegração corresponde à abstinência e à conquista de um emprego; busca-se a recuperação física a qualquer custo, relegando a segundo plano a vontade do sujeito. A influência do paradigma médico é evidente no funcionamento do serviço, com o usual protagonismo da "doença", em que o sucesso do tratamento depende exclusivamente de sua erradicação. O indivíduo é visto como incapaz de guiar sua vida, sendo tratado de forma infantilizada ou como "criatura", termo utilizado constantemente pela gerente do serviço. Contraditoriamente, é também considerado culpado por sua condição, o que se observa em discursos institucionais carregados de forte moralização e individualização de questões que envolvem múltiplos fatores, sobretudo as determinações sociais. O Consultório de Rua, a despeito de possuir o mesmo objetivo, visa alcançá-lo de forma espontânea, a partir da escolha pessoal e nunca de modo arbitrário e compulsório, à revelia da vontade do indivíduo.

Outro aspecto que reforça o antagonismo entre os equipamentos está relacionado à questão da recaída: a Moradia Assistida não a tolera sob nenhuma hipótese, ao passo que o Consultório de Rua a compreende como manifestação da liberdade do usuário, sem aplicação de nenhum tipo de punição.

Com base na análise dos dados coletados, pode-se afirmar que os equipamentos pesquisados se mostram representantes de suas respectivas políticas públicas. A Moradia Assistida, vinculada ao Programa Centro Legal, carrega em si os elementos que caracterizaram a operação militar e sanitária ocorrida no dia 03 de janeiro de 2012 na cidade de São Paulo: o esvaziamento da Cracolândia, a limpeza urbana, a repressão policial e o isolamento social. O Consultório de Rua, por sua vez, resultante do Projeto de Redução de Danos, preconiza a liberdade de reflexão, o direito de decisão, a autonomia para a ação e a participação ativa do sujeito no tratamento.

As diferenças entre os serviços são evidentes, o que não significa que sejam unificados e coesos, desprovidos de tensões internas. Embora o coordenador do Consultório de Rua se empenhe para eliminar qualquer vestígio do tratamento moralizante e 
corretivo, observa-se no serviço a presença de resquícios do discurso tradicional de modo que em seu interior coexistem forças conflitivas de caráter disciplinar e libertário. Na Moradia Assistida, por sua vez, a gerente procura elidir qualquer possibilidade de ação criativa; porém, os usuários de algum modo fazem resistência ao status quo organizacional, buscando romper com o poder instituído. Segundo Neto e cols. (2009), a saúde deve ser compreendida como um campo de tensões e antagonismos, atravessado tanto por forças regulatórias e padronizadoras quanto por forças emancipatórias e participativas.

\section{Referências}

Caldeira, T. P. R. Cidade de muros: crime, segregação e cidadania em São Paulo. São Paulo: Editora 34 e Edusp, 2000.

Campos, G. W. de S. Saúde pública e Saúde Coletiva: campo e núcleo de saberes e práticas. Ciência \& Saúde Coletiva, Rio de Janeiro, 2000, 5 (2): 219-230.

Canônico, R. P.; Tanaka, A. C. D’A.; Mazza, M. M. P. R.; Souza, M. de F.; Bernat, M. C. \& Junqueira, L. X. Atendimento à população de rua em um Centro de Saúde Escola na cidade de São Paulo. Revista da Escola de Enfermagem, São Paulo, 2007, 41: 799-803.

Carneiro Júnior, N.; Nogueira, E. A.; Lanferini, G. M.; Ali, D. A. \& Martinelli, M. Serviços de Saúde e População de Rua: contribuição para um debate. Saúde \& Sociedade, São Paulo, 1998, 7 (2): 47-62.

Carneiro Júnior, N. \& Silveira, C. Organização das práticas de atenção primária em saúde no contexto dos processos de exclusão/inclusão social. Cadernos de Saúde Pública, Rio de Janeiro, 2003, 19 (6): 1827-1835.

Carneiro Júnior, N.; Jesus, C. H. de \& Crevelim, M. A. A Estratégia Saúde da Família para a Equidade de Acesso dirigida à População em Situação de Rua em Grandes Centros Urbanos. Saúde \& Sociedade, São Paulo, 2010, 19 (3): 709-719.

Coelho, I. B. Formas de pensar e organizar o sistema de saúde: os modelos assistenciais em saúde. In: Campos, G. W. de S. \& Guerrero, A. V. P. (Org.). Manual de Práticas de Atenção Básica: saúde ampliada e compartilhada. São Paulo: editora Hucitec, 2010, 96131.

Costa, A. P. M. População em situação de rua: contextualização e caracterização. Revista Virtual Textos \& Contextos, Porto Alegre, 2005, 4 (01): 01-15.

Demo, P. Metodologia do Conhecimento Científico. São Paulo: Editora Atlas, 2011.

Di Flora, M. C. Mendigos: por que surgem, por onde circulam, como são tratados? Petrópolis: Vozes, 1987.

Foucault, M. Vigiar e Punir. São Paulo: Editora Vozes, 2006.

Fundação Escola de Sociologia e Política de São Paulo (FESP). Censo da População em situação de rua na municipalidade de São Paulo. São Paulo: Prefeitura da cidade de São Paulo, 2012.

Goffman, E. Estigma: notas sobre a manipulação da identidade deteriorada. Rio de Janeiro: LTC, 2008.

Loureiro, C. S. Reflexões sobre o trabalho com o outro a partir do fenômeno de jovens em situação de vulnerabilidade e de rua. In: Angelucci, C. B. (Org.). Álcool e outras drogas. 
São Paulo: Conselho Regional de Psicologia, 2012, p. 121-125.

Martins, R. e Vieira, W. Um flagelo político. Revista Carta Capital, São Paulo, 18 de Janeiro de 2012.

Matos, M. I. S. de. Em nome do engrandecimento da nação: representações de gênero no discurso médico - São Paulo 1890-1930. Diálogos, Paraná, 2000, 4 (4): 77-92.

Mattos, R. M. \& Ferreira, R. F. Quem vocês pensam que (elas) são? - representações sobre as pessoas em situação de rua. Psicologia \& Sociedade, Santa Catarina, 2004, 16 (2): 47-58.

Miranda, A. C. B. de C. Culpabilidade por vulnerabilidade: fundamentos para a exculpação ou redução de pena do pequeno traficante. Dissertação de Mestrado (Programa de Pósgraduação em Direito da Universidade Federal da Bahia). Salvador: UFBA, 2013.

Moreira, F. G.; Silveira, D. X \& Andreoli, S. B. Redução de danos do uso indevido de drogas no contexto da escola promotora de saúde. Ciência e Saúde Coletiva, Rio de Janeiro, 2006, 11 (3): 807-816.

Neto, J. L. F.; Kind, L.; Barros, J. S.; Azevedo, N. S. \& Abrantes, T. M. Apontamentos sobre promoção da saúde e biopoder. Saúde \& Sociedade, São Paulo, 2009, 18 (3): 456-466.

Nunes, E. D. Saúde Coletiva: história de uma ideia e de um conceito. Saúde \& Sociedade, São Paulo, 1994, 3 (2): 05-21.

Paim, J. S. \& Almeida Filho, N. de. Saúde coletiva: uma "nova saúde pública" ou campo aberto a novos paradigmas? Revista de Saúde Pública, São Paulo, 1998, 32 (4): 299-316.

Petuco, D. R. da S. Redução de Danos. In Angelucci, C. B. (Org.). Álcool e outras drogas. São Paulo: Conselho Regional de Psicologia, 2012, p.127-137.

Plena, M. G.; Giovanni, M.; Totugui, M. L.; Silva, V. C; Delgado, P. G. G. Consultório de Rua do SUS. Brasília: Ministério da Saúde, 2010.

Poupart, J. A entrevista de tipo qualitativo: considerações epistemológicas, teóricas e metodológicas. In: Poupart, J. et al. A pesquisa qualitativa: enfoques epistemológicos e metodológicos. Petrópolis, Rio de Janeiro: Editora Vozes, 2008, p. 215-253.

Rosen, G. Da polícia médica à medicina social. Rio de Janeiro, Graal, 1980.

Sodelli, M. A abordagem proibicionista em desconstrução: compreensão fenomenológica existencial do uso de drogas. Ciência \& Saúde Coletiva, Rio de Janeiro, 2010, 15 (3): 637-644.

Drogas e Ser Humano: a prevenção do possível. In: Angelucci, C. B. (Org.). Álcool e outras drogas. São Paulo: Conselho Regional de Psicologia, 2012, p. 15-21.

Souza, E. S. de; Silva, S. R. V. da \& Caricari, A. M. Rede social e promoção da saúde dos "descartáveis urbanos". Revista da Escola de Enfermagem, São Paulo, 2007, 41: 810- 